\title{
Reply to "Increasing Inpatient Consultation: Hospitalist Perceptions and Objective Findings. In Reference to: 'Hospitalist Perspective of Interactions with Medicine Subspecialty Consult Services'"
}

\author{
Traci N. Adams, MD* ${ }^{\star}$, Eli M. Miloslavsky, MD²
}

\begin{abstract}
'University of Texas Southwestern Department of Internal Medicine, Dallas, Texas; ${ }^{2}$ Massachusetts General Hospital-Division of Rheumatology, Boston, Massachusetts.
\end{abstract}

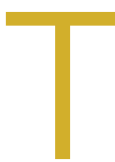

he finding by Kachman et al. that consultations have decreased at their institution is an interesting and important observation. ${ }^{1}$ In contrast, our study found that more than a third of hospitalists reported an increase in consultation requests. ${ }^{2}$ There may be several explanations for this discrepancy. First, as Kachman et al. suggest, there may be differences between hospitalist perception and actual consultation use. Second, a significant variability in consultation may exist between hospitals. Although our study examined four institutions, we were unable to examine the variability between them, which requires further study. Third, there may be considerable variability between individual hospitalist practices, which is consistent with the findings reported by Kachman et al. Finally, the fact that our study examined only nonteaching services may

*Address for correspondence: Traci Nicole Adams, MD, University of Texas Southwestern Department of Internal Medicine, 5323 Harry Hines Blvd, Dallas, Texas 75390-9030; Telephone: (214) 645-8300; Fax: (214) 645-6372; E-mail: tnfadams@gmail.com

Received: March 14, 2018; Accepted: March 24, 2018

@2018 Society of Hospital Medicine DOI 10.12788/jhm.2994 be another explanation as Kachman et al. found that hospitalists on nonteaching services ordered more consultations than those on teaching services. These findings are consistent with a recent study conducted by Perez et al., who found that hospitalists on teaching services utilized fewer consultations and had lower direct care costs and shorter lengths of stay compared with those on nonteaching services. ${ }^{3}$ This finding raises the question of whether consultations impact care costs and lengths of stay, a topic that should be explored in future studies.

Disclosures: The authors report no conflicts of interest.

\section{References}

1. Kachman M, Carter K, Martin S. Increasing inpatient consultation: hospitalist perceptions and objective findings. In Reference to: "Hospitalist perspective of interactions with medicine subspecialty consult services". J Hosp Med. 2018;13(11):802. doi: 10.12788/jhm.2992.

2. Adams TN, Bonsall $J$, Hunt $D$, et al. Hospitalist perspective of interactions with medicine subspecialty consult services. J Hosp Med. 2018;13(5):318323. doi: 10.12788/jhm.2882.

3. Perez JA Jr, Awar M, Nezamabadi A, et al. Comparison of direct patient care costs and quality outcomes of the teaching and nonteaching hospitalist services at a large academic medical center. Acad Med. 2018;93(3):491-497. doi: 10.1097/ACM.0000000000002026. 